Article

\title{
Inducing $\beta$ Phase Crystallinity in Block Copolymers of Vinylidene Fluoride with Methyl Methacrylate or Styrene
}

\author{
Nahal Golzari ${ }^{1}$, Jörg Adams ${ }^{2}$ and Sabine Beuermann ${ }^{1, *}$ \\ 1 Institute of Technical Chemistry, Clausthal University of Technology, Arnold-Sommerfeld-Strasse 4, \\ 38678 Clausthal-Zellerfeld, Germany; nahal.golzari@tu-clausthal.de \\ 2 Institute of Physical Chemistry, Clausthal University of Technology, Arnold-Sommerfeld-Strasse 4, \\ 38678 Clausthal-Zellerfeld, Germany; adams@pc.tu-clausthal.de \\ * Correspondence: sabine.beuermann@tu-clausthal.de; Tel.: +49-532-372036
}

Received: 20 June 2017; Accepted: 20 July 2017; Published: 26 July 2017

\begin{abstract}
Block copolymers of poly(vinylidene fluoride) (PVDF) with either styrene or methyl methacrylate (MMA) were synthesized and analyzed with respect to the type of the crystalline phase occurring. PVDF with iodine end groups (PVDF-I) was prepared by iodine transfer polymerization either in solution with supercritical $\mathrm{CO}_{2}$ or in emulsion. To activate all iodine end groups $\mathrm{Mn}_{2}(\mathrm{CO})_{10}$ is employed. Upon UV irradiation $\mathrm{Mn}(\mathrm{CO})_{5}$ radicals are obtained, which abstract iodine from PVDF-I generating PVDF radicals. Subsequent polymerization with styrene or methyl methacrylate (MMA) yields block copolymers. Size exclusion chromatography and NMR results prove that the entire PVDF-I is converted. XRD, FT-IR, and differential scanning calorimetry (DSC) analyses allow for the identification of crystal phase transformation. It is clearly shown that the original $\alpha$ crystalline phase of PVDF-I is changed to the $\beta$ crystalline phase in case of the block copolymers. For ratios of the VDF block length to the MMA block length ranging from 1.4 to 5 only $\beta$ phase material was detected.
\end{abstract}

Keywords: fluoropolymers; vinylidene fluoride; block copolymers; crystallization; phase separation

\section{Introduction}

Most hydrofluorocarbon polymers show extraordinary thermal stability, chemical inertness, and weatherability, as well as being stable against various types of radiation. Large scale applications encompass, e.g., coatings, membranes, tubes, and piping equipment [1,2] Poly(vinylidene fluoride) (PVDF) is special, because additionally it shows ferro-, piezo-, and pyroelectric properties [3-10]. These electroactive properties are associated with the all trans conformation $\beta$ crystalline phase of PVDF. However, the semi-crystalline polymer forms not only $\beta$ phase material, but four more polymorphs $(\alpha, \gamma, \delta$, and $\varepsilon$ phase) which are known [11,12].

The $\alpha$ polymorph is the most readily available phase. Several processes were reported to obtain $\beta$ phase material, such as ultrafast cooling, melting under high pressure, mechanical stretching of the $\alpha$ polymorph, and blending with poly(methyl methacrylate) (PMMA), $\mathrm{BaTiO}_{3}$ or palladium. An excellent overview on the various phases of PVDF and applications as electroactive materials is presented in reference [13]. In addition to the homopolymer of vinylidene fluoride (VDF), in binary and ternary copolymers of VDF with trifluoroethylene and chlorotrifluoroethylene $\beta$ phase formation is found $[3,14,15]$. Due to higher sterical hindrance compared to VDF homopolymers the formation of the all trans $\beta$ phase is preferred [13].

Frequently, blends of PVDF and PMMA are considered for $\beta$ phase formation [16] due to favorable interactions between the highly electronegative $\mathrm{F}$ atoms in PVDF and the carbonyl groups of PMMA. Moreover, steric reasons are supposed to favor the trans conformation of both polymers and may lead 
to a chain extension and consequently $\beta$ crystallinity is promoted [16]. In addition, the influence of the glass transition temperature, $T_{\mathrm{g}}$, on the relative growth rates of $\alpha$ and $\beta$ spherulites is discussed [16]. Depending on polymer molecular weights and the ratio of both polymers in the blend, phase separation may occur. If phase separation in polymer blends induces $\beta$ phase crystallinity of the PVDF domains, it appears particularly interesting to consider block copolymers consisting of one PVDF block. Again, phase separation is expected to occur and $\beta$ phase crystallinity should occur.

So far the number of reports on PVDF block copolymers is still rather small. Reversible deactivation transfer polymerizations frequently used for block copolymer synthesis of styrene and many (meth)acrylate monomers are difficult to be performed with VDF, mainly due to the highly reactive primary propagating radical. Methods involving degenerative chain transfer constitute an exception from the above said. Iodine transfer polymerizations (ITP) [17-20], the use of xanthates [21-24] or reversible addition fragmentation transfer (RAFT) polymerizations [25,26] allow for good control of molecular weights, result in low dispersities, and may yield block copolymers.

Generally, in ITP perfluorinated alkyl iodides such as $\mathrm{C}_{6} \mathrm{~F}_{13} \mathrm{I}$ or $\mathrm{C}_{6} \mathrm{~F}_{12} \mathrm{I}_{2}$ are used as chain transfer agents $[19,20]$. Due to the rather low bond energy between iodine and the propagating chain, the transfer reaction of iodine is reversible. Regular head to tail addition leads to $-\left(\mathrm{CF}_{2}-\mathrm{CH}_{2}\right)-$ motifs in the polymer chain. Further, tail to tail, tail to head, and head to head additions play an important role in VDF polymerizations leading to $-\mathrm{CF}_{2}-\mathrm{CH}_{2}-\mathrm{CH}_{2}-\mathrm{CF}_{2}-$ and $-\mathrm{CH}_{2}-\mathrm{CF}_{2}-\mathrm{CF}_{2}-\mathrm{CH}_{2}-$ sequences in the polymer chains as well as $-\mathrm{CH}_{2}-\mathrm{CF}_{2}-\mathrm{I}$ and $-\mathrm{CF}_{2}-\mathrm{CH}_{2}-\mathrm{I}$ end groups as identified by NMR spectroscopy. $-\mathrm{CH}_{2}-\mathrm{CF}_{2}-\mathrm{I}$ is at least 25 times more active than $-\mathrm{CF}_{2}-\mathrm{CH}_{2}-\mathrm{I}$ [27]. As a consequence, the fraction of inactive $-\mathrm{CF}_{2}-\mathrm{CH}_{2}-\mathrm{I}$ chain ends increases with conversion. Previously, the active species, $-\mathrm{CH}_{2}-\mathrm{CF}_{2}-\mathrm{I}$, was used for follow-up reactions [28-30]. In all cases, only the polymer with active end groups was used.

Asandei and coworkers reported a synthetic strategy using $\mathrm{Mn}_{2}(\mathrm{CO})_{10}$ for activation of both iodine polymer end groups, consequently allowing for an efficient transformation of all polymer chains [31-33]. Since the linkage between two Mn atoms is weak (20-40 kJ) [34,35], visible light allows for the production of two ${ }^{\bullet} \mathrm{Mn}(\mathrm{CO})_{5}$ metalloradicals with good quantum efficiency [36]. ${ }^{\bullet} \mathrm{Mn}(\mathrm{CO})_{5}$ radicals being very good halide abstractors irreversibly activate both iodine end groups originating from ITP and $\mathrm{Mn}(\mathrm{CO})_{5}-\mathrm{I}$ is formed [31]. Both radicals obtained $\left(-\mathrm{CF}_{2}{ }^{\bullet}\right.$ and $\left.-\mathrm{CH}_{2}{ }^{\bullet}\right)$ may react with an added monomer to initiate a free radical polymerization leading to block copolymers where PVDF-I serves as a macroinitiator.

A different synthetic strategy is the preparation of block copolymers via functional benzoyl peroxide initiated polymerization of VDF and subsequent synthesis of the second block using atom transfer radical polymerization or ring opening polymerization [37-39]. For example, the resulting block copolymers with the second block being poly(butyl methacrylate) showed $\beta$ phase crystallinity of the PVDF block with a molecular weight of around $15,000 \mathrm{~g} \cdot \mathrm{mol}^{-1}$ and a PVDF molar content of around 0.5 .

Due to the above mentioned favorable interactions and the associated miscibility of PMMA and PVDF, in this contribution the synthesis of block copolymers of VDF with MMA is reported. In addition, some copolymers with styrene as the second monomer were prepared. Firstly, PVDF-I was synthesized by ITP in supercritical carbon dioxide as solvent [40,41] or in emulsion [42]. Then, with PVDF-I as macroinitiator $\mathrm{Mn}_{2}(\mathrm{CO})_{10}$-photomediated free radical polymerization with MMA or styrene were carried out to yield well-defined block copolymers. The molecular weight of the initial PVDF macroinitiator and the ratio of the block lengths was varied. Atomic Force Microscopy (AFM) of thin films is considered to identify phase separation of both polymer blocks. In order to identify whether the PVDF domains are crystalline and to analyze which type of crystalline phase is determined, Fourier transform infrared spectroscopy (FTIR), X-ray powder diffraction (XRD), and differential scanning calorimetry (DSC) were used. 


\section{Methods and Materials}

\subsection{Materials}

Vinylidene fluoride (VDF, Dyneon GmbH, Burgkirchen a.d.Alz, Germany, 99.5\%), styrene (S, Sigma-Aldrich, Taufkirchen, Germany, 99.5\%), methyl methacrylate (MMA, Sigma-Aldrich, Taufkirchen, Germany, 99\%), di-tert-butylperoxide (DTBP, Merck, Darmstadt, Germany, 98\%), 1-iodoperfluorohexane (ABCR, Karlsruhe, Germany, 99\%), 1,4-diiodooctafluorobutane (Dyneon $\mathrm{GmbH}$, Burgkirchen a.d.Alz, Germany), dimanganese decacarbonyl (Sigma-Aldrich, Taufkirchen, Germany, 98\%), methanol (95\%), hydrochloric acid (37\%), N,N-dimethyl acetamide (DMAc, Acros, Geel, Belgium, 99\%), ammonium 4,8-dioxa-3H-perfluorononanoate (Dyneon, $\mathrm{GmbH}$, Burgkirchen a.d.Alz, Germany), ammonium peroxydisulfate (Fluka, Honeywell, Hannover, Germany, $\geq 98.0 \%$ ), carbon dioxide (Air Liquide, Paris, France, 99.8\%), N,N-dimethylformamide- $\mathrm{d}_{7}$ (Deutero $\mathrm{GmbH}$, Kastellaun, Germany, 99.5\%), and acetone- $\mathrm{d}_{6}$ (Deutero $\mathrm{GmbH}$, Kastellaun, Germany, 99.8\%) were used as received.

\subsection{Characterization}

To characterize the polymers, the following techniques and equipment were used. Size-exclusion chromatography (SEC) measurements were carried out at a column temperature of $45{ }^{\circ} \mathrm{C}$ using DMAc, which contains $0.1 \% \mathrm{LiBr}$ as eluent. The SEC set-up consists of an Agilent 1200 isocratic pump, an Agilent 1200 refractive index detector, and four PSS GRAM columns (Guard, $100 \AA$, $3000 \AA$, and $3000 \AA$ ) from Polymer Standard Service (PSS). Measurements were carried out at a flow rate of $1 \mathrm{~mL} \cdot \mathrm{min}^{-1}$. Polystyrene standards (PSS) were used for calibration. For FT-IR measurements a Vertex 70 Bruker spectrometer (Bruker Optik $\mathrm{GmbH}$, Bremen, Germany) equipped with a globar source and a photoacoustic cell (PA301) was used. Spectra were measured with a resolution of $4 \mathrm{~cm}^{-1} \cdot{ }^{1} \mathrm{H}$ and ${ }^{19} \mathrm{~F}$ NMR spectra of the polymers were recorded on a Bruker AVANCE $400 \mathrm{MHz}$ spectrometer at room temperature. Acetone- $\mathrm{d}_{6}$ and also $\mathrm{N}, \mathrm{N}$-dimethylformamide- $\mathrm{d}_{7}$ were used as solvents. To characterize the phase separation of the copolymers, thin polymer films were prepared either by casting a solution directly onto clean mica or by spin coating onto the same substrate $(5 \mathrm{mg}$ polymer in $1 \mathrm{~mL}$ DMAc, spin-coater WS-650MZ, Laurell, North Wales, PA, USA). These films were analyzed with an AFM (extended multimode, NanoScope IIIa controller, Veeco/Digital Instruments, Plainview, NY, USA) operating in tapping mode at room temperature in air. To selectively etch the PMMA or PS blocks while keeping the PVDF intact, air-plasma generated in a RF plasma cleaner (PDC-32G, Harrick-Plasma, Ithaca, NY, USA) was used for up to $60 \mathrm{~s}$. This technique has been used successfully to contrast PS in PMMA-PS block copolymers [43]. XRD analyses at KIT were conducted by a STADI MP diffractometer (STOE, Darmstadt, Germany) with Ge-monochromatized $\mathrm{Cu}-\mathrm{K} \alpha$ radiation $(\lambda=1.54060 \AA)$. The XRD measurements at TUC were conducted with $\mathrm{Cu}-\mathrm{K} \alpha$ (graphite monochromator) as well. A Bruker AXS D8 Discover diffractometer was used, equipped with a General Area Diffraction System (GADDS, Bremen, Germany) as detector. DSC measurements were performed with a DSC 1/500658/200W STARe system by Mettler Toledo, Columbus, OH, USA. This system is equipped with a FRS5 sensor and liquid nitrogen cooling. Each sample passes through a complete heating and cooling cycle before the second heating run is used for analysis. The heating or cooling rate is $10^{\circ} \mathrm{C} \cdot \mathrm{min}^{-1}$ for all measurements.

\subsection{Synthesis of PVDF-I}

Polymers with iodine end group (PVDF-I) were synthesized by iodine transfer polymerization (ITP). $\mathrm{C}_{6} \mathrm{~F}_{13} \mathrm{I}$ was used as the chain transfer agent, DTBP as the initiator, and $\mathrm{CO}_{2}$ as the solvent. A typical experiment was performed at a constant temperature of $120^{\circ} \mathrm{C}$ and an initial pressure of 1500 bar. During polymerization the pressure decreased to around 850 bar due to volume contraction upon consumption of the gaseous monomer. To produce PVDF homopolymers with a number average molecular weight, $M_{\mathrm{n}}$, between 1500 and $2500 \mathrm{~g} \cdot \mathrm{mol}^{-1}$, a weight fraction of VDF of around $70 \%$, 
$1.5 \mathrm{~g}$ DTBP $\left(10.4 \mathrm{mmol}, c=0.076 \mathrm{~mol} \cdot \mathrm{L}^{-1}\right)$, and $8.0 \mathrm{~g} \mathrm{C}_{6} \mathrm{~F}_{13} \mathrm{I}\left(1.8 \mathrm{mmol}, c=0.13 \mathrm{~mol} \cdot \mathrm{L}^{-1}\right)$ were used. PVDF-I with $M_{\mathrm{n}}>10^{4} \mathrm{~g} \cdot \mathrm{mol}^{-1}$ was obtained from reactions with reduced quantities of initiator and chain transfer agent: $0.75 \mathrm{~g}$ DTBP $\left(5.1 \mathrm{mmol}, c=0.056 \mathrm{~mol} \cdot \mathrm{L}^{-1}\right)$ and $4.0 \mathrm{~g} \mathrm{C}_{6} \mathrm{~F}_{13} \mathrm{I}(9.0 \mathrm{mmol}$, $c=0.097 \mathrm{~mol} \cdot \mathrm{L}^{-1}$ ) were used. The preparation of the reaction mixture, the polymerization procedure, and the reaction set-up were detailed elsewhere [40].

I-PVDF-I used for samples 2 and 3 is synthesized by emulsion polymerization. The reaction was performed at $90{ }^{\circ} \mathrm{C}$ and 15 bar for $4 \mathrm{~h}$. Ammonium 4,8-dioxa-3H-perfluorononanoate was used as the surfactant $\left(0.022 \mathrm{~mol} \cdot \mathrm{L}^{-1}\right)$, ammonium peroxydisulfate as the initiator $\left(6 \mathrm{mmol} \cdot \mathrm{L}^{-1}\right)$ and $\mathrm{C}_{4} \mathrm{~F}_{8} \mathrm{I}_{2}$ as the chain transfer agent $\left(12 \mathrm{mmol} \cdot \mathrm{L}^{-1}\right)$ [42].

The number average molecular weights $M_{\mathrm{n}}$ and dispersities of the PVDF homopolymers are listed in Table 1. It should be noted that $M_{n}$ data refers to SEC calibration with polystyrene standards. In order to estimate absolute molecular weights the principle of universal calibration was applied [44]. With Mark-Houwink parameters $K$ and $a$ being known for polystyrene and for PVDF in dimethyl acetamide as eluent [45], $M_{n}$ values are derived, which are about $15 \%$ lower than the $M_{n}$ values listed in Table 1 . Since the $K$ and $a$ values were derived from a higher molecular weight sample, and since SEC is generally considered to be associated with an uncertainty of $10 \%$ to $15 \%$, we decided on listing the data derived from the primary experimental data.

\subsection{Synthesis of the Block Copolymers (PVDF-b-PMMA and PVDF-b-PS)}

In a round-bottom flask, $100 \mathrm{mg}$ of PVDF-I (or I-PVDF-I), $1 \mathrm{~mL}$ of the other monomer (MMA, $9.4 \mathrm{mmol}$ or styrene $9.1 \mathrm{mmol})$ and $36 \mathrm{mg}$ of $\mathrm{Mn}_{2}(\mathrm{CO})_{10}(0.092 \mathrm{mmol})$ were dissolved in $2 \mathrm{~mL}$ DMAc. In addition, reactions with different amounts of the monomers (see Table 1 ) were carried out. The mixture was purged with $\mathrm{N}_{2}$ for $10 \mathrm{~min}$, then placed in an oil-bath, and stirred at $90{ }^{\circ} \mathrm{C}$ under visible light irradiation (Oriel 60006 lamp, LOT group, Darmstadt, Germany) for $1 \mathrm{~h}$. As suggested by Asandei and coworkers [31], the polymer was precipitated in acidic methanol, filtered, and dried.

\section{Results and Discussion}

ITP of VDF with perfluorinated alkyl iodides serving as chain transfer agents lead to polymers with the following two end groups: $-\mathrm{CF}_{2}-\mathrm{CH}_{2}-\mathrm{I}$ and $-\mathrm{CH}_{2}-\mathrm{CF}_{2}-\mathrm{I}$ [27]. As reported by Asandei and coworkers, the ${ }^{\bullet} \mathrm{M}_{\mathrm{n}}(\mathrm{CO})_{5}$ radical obtained upon UV irradiation of $\mathrm{Mn}_{2}(\mathrm{CO})_{10}$ may abstract I from both chain ends [31]. In the following the PVDF chain extension and block copolymer synthesis based on the use of $\mathrm{Mn}_{2}(\mathrm{CO})_{10}$ is described.

\subsection{Chain Extension of PVDF}

For block copolymer synthesis PVDF samples with different molecular weights were used. In addition, the amount of macroinitiator and comonomer were varied. Details are displayed in Table 1 . In every case, $36 \mathrm{mg}$ of $\mathrm{Mn}_{2}(\mathrm{CO})_{10}, 2 \mathrm{~mL}$ of DMAc and a reaction time of $1 \mathrm{~h}$ were chosen. The results of PVDF macroinitiator and copolymer SEC analyses as well as copolymer compositions derived from NMR analyses are also listed in Table 1.

Samples 2 and 3 were obtained with identical amounts of macroinitiator I-PVDF-I and different amounts of MMA. As expected, the higher MMA concentration leads to significantly higher block copolymer molecular weights. Samples 1, 4, and 5 show that variation of PVDF molecular weight at otherwise identical conditions leads to block copolymers with significantly enhanced molecular weights, while dispersities are slightly lower than for the macroinitiator.

In order to test for the formation of block copolymers the molecular weight distributions (MWDs) are considered. While SEC does not give any information on the absolute molecular weights and block lengths due to calibration relative to polystyrene, the position of the MWDs provides information on the chain extension. As an example, Figure 1 gives the MWDs of the macroinitiator and a copolymer containing PMMA as the second block. The block copolymer MWD is clearly shifted to higher 
molecular weight compared to the MWD of the PVDF-I macroinitiator, which indicates a successful chain extension.

Table 1. Details of block copolymer synthesis and resulting block copolymers properties with the amount of macroinitiator $m_{\mathrm{PVDF}}$, the volume of comonomer $V_{\mathrm{co}}$, molecular weights $\left(M_{\mathrm{n}, \mathrm{block}}\right)$, dispersities $\left(D_{\text {block }}\right)$, molar ratio of $\mathrm{VDF}$ and comonomer $\left(n_{\mathrm{VDF}} / n_{\mathrm{co}}\right)$, and volume fraction of the comonomer in the copolymer. $M_{\mathrm{n}, \mathrm{PVDF}}$ and $D_{\mathrm{PVDF}}$ refer to the PVDF-I ${ }^{\mathrm{a}}$ or I-PVDF-I ${ }^{\mathrm{b}}$ macroinitiator.

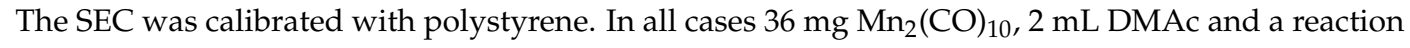
time of $1 \mathrm{~h}$ were chosen.

\begin{tabular}{|c|c|c|c|c|c|c|c|c|c|c|c|}
\hline No. & $\begin{array}{l}M_{\mathrm{n}, \mathrm{PVDF}} / \\
\mathrm{g} \cdot \mathrm{mol}^{-1}\end{array}$ & $D_{\text {PVDF }}$ & $\begin{array}{c}m_{\mathrm{PVDF}} / \\
\mathrm{mg}\end{array}$ & Comonomer & $\begin{array}{l}V_{\mathrm{co}} / \\
\mathrm{mL}\end{array}$ & $\begin{array}{l}M_{\mathrm{n}, \mathrm{block}}{ }^{\prime} \\
\mathrm{g} \cdot \mathrm{mol}^{-1}\end{array}$ & $D_{\text {block }}$ & $n_{\mathrm{VDF}} / n_{\mathrm{co}}$ & $n_{\mathrm{VDF}}$ & $n_{\text {co }}$ & $\varphi_{\mathrm{co}}$ \\
\hline $1^{a}$ & 2033 & 1.5 & 100 & MMA & 1 & 22,344 & 1.6 & $1 / 3$ & 27 & 81 & 0.84 \\
\hline $3^{b}$ & 4344 & 2.0 & 100 & MMA & 4 & 40,524 & 1.8 & $1 / 4$ & 58 & 232 & 0.87 \\
\hline $4^{\mathrm{a}}$ & 4518 & 1.4 & 100 & MMA & 1 & 39,450 & 1.8 & $1 / 2.3$ & 60 & 138 & 0.85 \\
\hline $5^{a}$ & 11,500 & 1.4 & 100 & MMA & 1 & 50,520 & 1.7 & $1 / 0.67$ & 153 & 102 & 0.58 \\
\hline $8^{a}$ & 11,500 & 1.4 & 100 & MMA & 1.5 & 60,880 & 2.1 & $1 / 0.84$ & 153 & 128 & 0.66 \\
\hline $9^{a}$ & 2033 & 1.5 & 100 & $S$ & 1 & 13,220 & 3.6 & $1 / 0.56$ & 27 & 15 & 0.59 \\
\hline $10^{\mathrm{a}}$ & 11,500 & 1.4 & 100 & S & 3 & 33,040 & 1.3 & $1 / 0.91$ & 153 & 140 & 0.58 \\
\hline $11^{a}$ & 11,500 & 1.4 & 200 & S & 1 & 19,856 & 1.9 & $1 / 0.71$ & 153 & 109 & 0.50 \\
\hline $12^{a}$ & 11,500 & 1.4 & 200 & S & 2 & 21,669 & 1.7 & $1 / 0.77$ & 153 & 118 & 0.54 \\
\hline
\end{tabular}

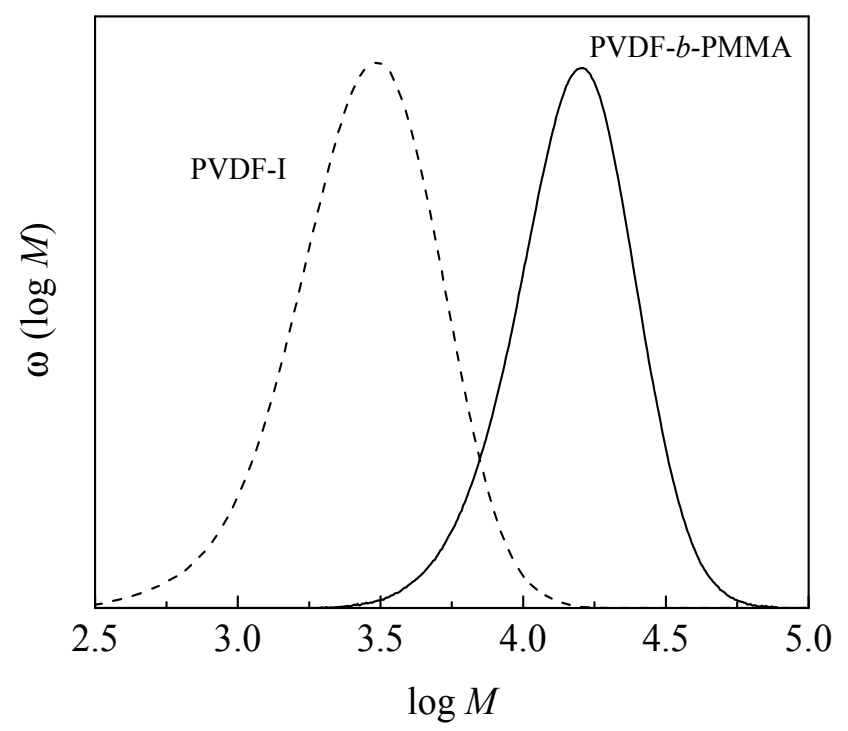

Figure 1. Molecular weight distributions poly(vinylidene fluoride) with iodine end groups (PVDF-I). PVDF-I (dashed) and resulting block copolymer with methyl methacrylate (MMA) (full, sample 1).

SEC elution chromatograms were analyzed to evaluate whether the entire PVDF-I macroinitiator was transformed. As an example, Figure 2 gives the SEC elution curves for PVDF-I with $M_{\mathrm{n}}=2033 \mathrm{~g} \cdot \mathrm{mol}^{-1}$ and the block copolymer sample 1 . The negative peak assigned to PVDF-I occurs at an elution time of $31 \mathrm{~min}$, whereas the chromatogram of the block copolymer does not show any contributions from PVDF-I at $31 \mathrm{~min}$. The elution curves of all other copolymers listed in Table 1 show no peak originating from PVDF-I. Contrary to reference [31] where a reaction time of $5 \mathrm{~h}$ and a temperature of $110^{\circ} \mathrm{C}$ were selected, here $1 \mathrm{~h}$ and $90^{\circ} \mathrm{C}$ were sufficient for complete conversion of the macroinitiator. The difference is suggested to be due to differences in UV irradiation and consequently differences in the generation of $\bullet \mathrm{Mn}(\mathrm{CO})_{5}$ radicals. 


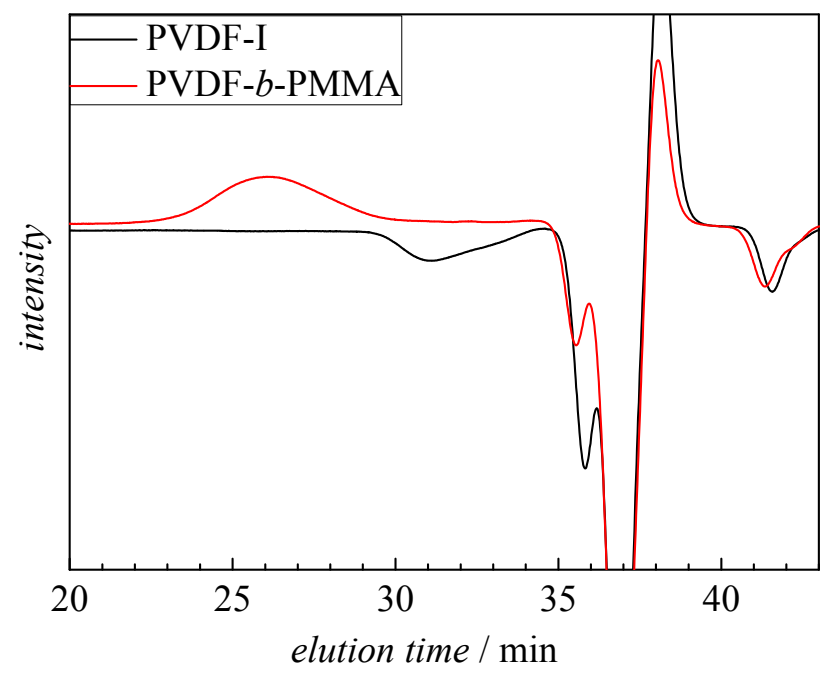

Figure 2. Elution curve of PVDF-I with $M_{\mathrm{n}}=2033 \mathrm{~g} \cdot \mathrm{mol}^{-1}$ and copolymer sample 1 .

\subsection{Block Copolymer Composition}

Since the dispersities of PVDF-I and the block copolymer are rather close, it is anticipated that both chain ends, the $\mathrm{CF}_{2}-\mathrm{I}$ and the $\mathrm{CH}_{2}-\mathrm{I}$ end group, were transformed. To prove whether both end groups were activated and polymerized, end group analyses were carried out via ${ }^{1} \mathrm{H}$ and ${ }^{19} \mathrm{~F} \mathrm{NMR}$ spectroscopy. Firstly, a blank reaction of PVDF-I and $\mathrm{Mn}_{2}(\mathrm{CO})_{10}$ in the absence of comonomer is considered. The reaction was performed with $100 \mathrm{mg}$ PVDF-I dissolved in $3 \mathrm{~mL}$ DMAc containing $36 \mathrm{mg}$ of $\mathrm{Mn}_{2}(\mathrm{CO})_{10}(0.092 \mathrm{mmol})$ under UV irradiation at $40{ }^{\circ} \mathrm{C}$ for $3 \mathrm{~h}$. The PVDF radical formed was expected to abstract an $\mathrm{H}$ atom either from the solvent or from the polymer. Figure 3 shows ${ }^{1} \mathrm{H}$ NMR spectra of the original material (denoted PVDF-I) and PVDF obtained from the blank reaction (denoted PVDF-H). As expected PVDF-I shows both iodine end groups. According to reference [20] the peak at $\sim 3.6 \mathrm{ppm}$ is assigned to $-\mathrm{CH}_{2}-\mathrm{CF}_{2}-\mathrm{I}$ and the peak at around $3.8 \mathrm{ppm}$ refers to $-\mathrm{CF}_{2}-\mathrm{CH}_{2}-\mathrm{I}$. Both peaks are only very weak in the spectrum of PVDF-H. Instead, a peak at about $6.3 \mathrm{ppm}$ is found, which refers to $-\mathrm{CH}_{2}-\mathrm{CF}_{2}-\underline{\mathrm{H}}$ being due to transfer to solvent or polymer [46]. The red spectrum referring to $\mathrm{PVDF}-\mathrm{H}$ also shows a peak at about $1.75 \mathrm{ppm}$, which represents $-\mathrm{CF}_{2}-\mathrm{CH}_{3}$ originating from $-\mathrm{CF}_{2}-\mathrm{CH}_{2}-\mathrm{I}$ after replacing I with $\mathrm{H}$ [46]. The single peak at $\delta \sim 4.55 \mathrm{ppm}$ indicates the presence of $-\mathrm{CH}_{2}-\mathrm{CF}_{2}-\mathrm{CH}=\mathrm{CF}_{2}$ [31], which originates from termination via disproportionation. Peaks at $\delta$ $\sim 2.19$ and $2.13 \mathrm{ppm}$ represent the $-\mathrm{CH}_{2}-\mathrm{CF}_{2}-\mathrm{CH}=\mathrm{CF}_{2}$ motif. The strong peak at $\delta \sim 2.8-3.0 \mathrm{ppm}$ in both spectra refers to the $-\left[\mathrm{CH}_{2}-\mathrm{CF}_{2}\right]_{n}$ - head to tail PVDF sequence. The $-\mathrm{CF}_{2}-\mathrm{CH}_{2}-\mathrm{CH}_{2}-\mathrm{CF}_{2}-$ head to head PVDF sequence is associated with a peak at $\delta \sim 2.4$ which is however hardly seen in both spectra due to the very low $M_{\mathrm{n}}$ and consequently a small quantity of this sequence in the material. The acetone peak is seen around $2.05 \mathrm{ppm}[46,47]$. 


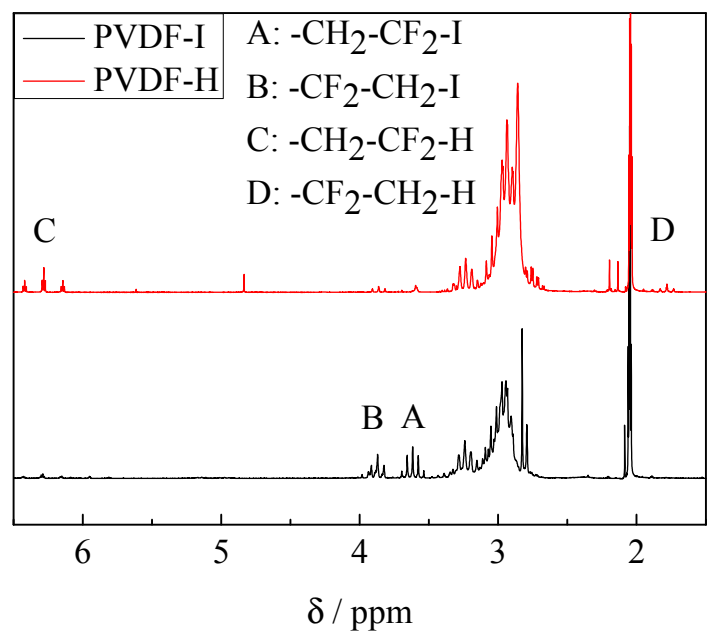

Figure 3. ${ }^{1} \mathrm{H}$ NMR spectra of PVDF-I (black) and PVDF-H (red).

The ${ }^{1} \mathrm{H}$ NMR spectrum in Figure 4 recorded for a block copolymer of VDF and MMA shows the expected peaks. The very strong peak at about $3.6 \mathrm{ppm}$ is assigned to the $-\mathrm{OC}_{3}$ group of PMMA and two strong peaks between 0.8 and $1.2 \mathrm{ppm}$ to the $-\mathrm{CH}_{3}$ group at the main chain of PMMA. In addition, the above-mentioned peaks assigned to the methylene group of PVDF at 2.4 and $3.0 \mathrm{ppm}$ are seen. Integration of the peak at $\delta \sim 3.6 \mathrm{ppm}$ for PMMA and at $\delta \sim 2.4$ and $3.0 \mathrm{ppm}$ for PVDF allows for the calculation of the ratio of block lengths according to Equation (1).

$$
\frac{n_{\mathrm{PMMA}}}{n_{\mathrm{PVDF}}}=\frac{\frac{1}{3} \int \mathrm{CH}_{3}(3.6 \mathrm{ppm})}{\frac{1}{2} \int \mathrm{CH}_{2}(3.0 \mathrm{ppm})+\frac{1}{2} \int \mathrm{CH}_{2}(2.4 \mathrm{ppm})}
$$

The example in Figure 4 represents a block copolymer with $n_{\text {PVDF }}$ to $n_{\text {PMMA }}$ of 1 to 0.67 (sample 5). The results for all block copolymers are given in Table 1 .

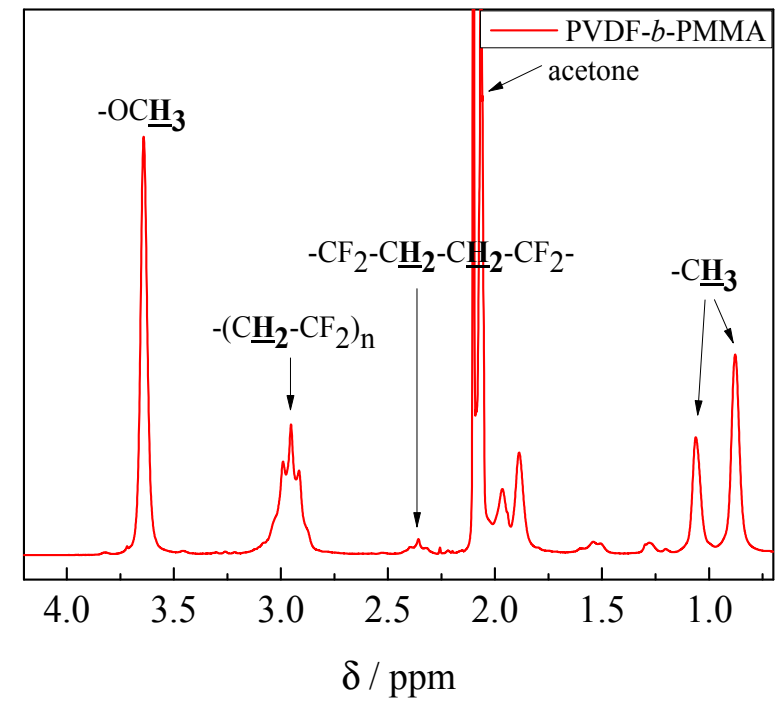

Figure 4. ${ }^{1} \mathrm{H}$ NMR spectrum of block copolymer sample 5 .

The ${ }^{1} \mathrm{H}-\mathrm{NMR}$ spectrum in Figure 5 recorded for a block copolymer consisting of VDF and styrene shows also the expected peaks. The strong peaks at around 6.6 to $7.2 \mathrm{ppm}$ are assigned to the $-\mathrm{C}_{6} \underline{\mathrm{H}}_{5}$ 
group of PS. Two other peaks at $1.94 \mathrm{ppm}\left(-\mathrm{CH}_{2}-\mathrm{CH}-\left(\mathrm{C}_{6} \mathrm{H}_{5}\right)-\right)$ and $1.63 \mathrm{ppm}\left(-\mathrm{CH}_{2}-\mathrm{CH}-\left(\mathrm{C}_{6} \mathrm{H}_{5}\right)-\right)$ also belong to PS. In addition, the peaks at 3.0 and $2.4 \mathrm{ppm}$ assigned to the methylene groups in PVDF are seen. Integration of the peaks at 6.6 to $7.2 \mathrm{ppm}$ for PS and at 2.4 and $3.0 \mathrm{ppm}$ for PVDF allows for the calculation of the ratio of block lengths according to Equation (2).

$$
\frac{n_{\mathrm{PS}}}{n_{\mathrm{PVDF}}}=\frac{\frac{1}{5} \int \mathrm{C}_{6} \mathrm{H}_{5}(6.6 \text { to } 7.2 \mathrm{ppm})}{\frac{1}{2} \int \mathrm{CH}_{2}(3.0 \mathrm{ppm})+\frac{1}{2} \int \mathrm{CH}_{2}(2.4 \mathrm{ppm})}
$$

The example in Figure 5 represents a block copolymer with $n_{\mathrm{PVDF}}$ to $n_{\mathrm{PS}}$ of 1 to 0.56 . The results for all block copolymers containing styrene are listed in Table 1.

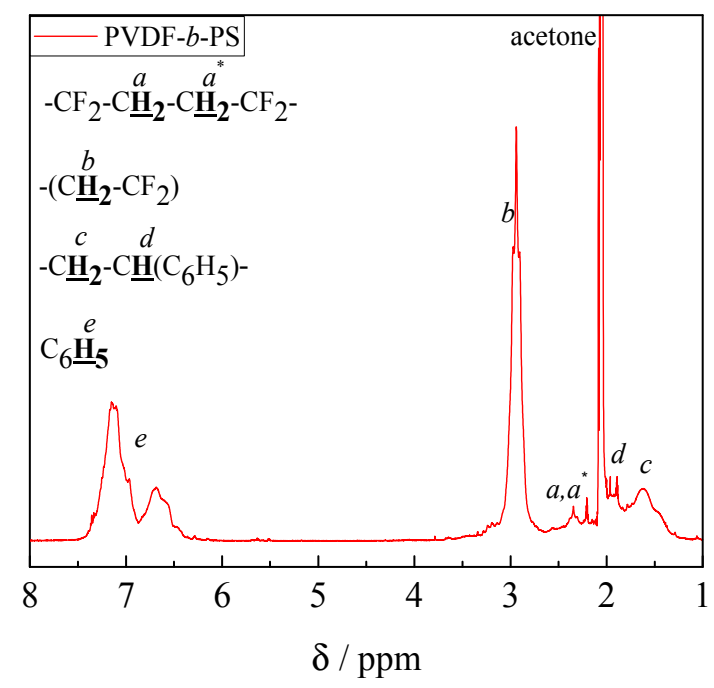

Figure 5. ${ }^{1} \mathrm{H}$ NMR spectrum of block copolymer sample 9 .

The ${ }^{19} \mathrm{~F}-\mathrm{NMR}$ results also show that $-\mathrm{CH}_{2}-\mathrm{CF}_{2}-\mathrm{I}$ and $-\mathrm{CF}_{2}-\mathrm{CH}_{2}-\mathrm{I}$ chain ends of the PVDF macroinitiator were activated and polymerized. Peaks at $\delta \sim-38.4 \mathrm{ppm}$ and $\delta \sim-108 \mathrm{ppm}$ referring to $-\mathrm{CH}_{2}-\mathrm{CF}_{2}-\mathrm{I}$ and $-\mathrm{CF}_{2}-\mathrm{CH}_{2}-\mathrm{I}$ [31,47] respectively, of the macroinitiator clearly disappeared after copolymerization (see Figure $\mathrm{S} 1$ in Supporting Information).

\subsection{Crystallinity of the Block Copolymers}

To obtain additional information on the crystallinity of the products, FT-IR spectra were recorded. The FT-IR spectra of PVDF homopolymer and the block copolymers are given in Figure 6. One of the most prominent difference is the strong band at $1730 \mathrm{~cm}^{-1}$, which is assigned to the carbonyl group in PMMA (blue spectrum) which is absent in the PVDF spectrum. In addition, the IR spectrum of the PMMA block copolymer shows a broad peak at $2951 \mathrm{~cm}^{-1}$ assigned to $-\mathrm{OCH}_{3}$ of PMMA. The spectrum of the block copolymer with PS (red spectrum) shows the aromatic $\mathrm{C}-\mathrm{H}$ stretching vibrations at 2850, 2923, 3025, and $3060 \mathrm{~cm}^{-1}$. The peaks at 1493 and $1062 \mathrm{~cm}^{-1}$ are assigned to the aromatic $C-C$ bond stretching vibration. The absorbances at 3000 and $3100 \mathrm{~cm}^{-1}$ represent the $C-C$ vibrations and peaks at $1151 \mathrm{~cm}^{-1}$, as well as at $1193 \mathrm{~cm}^{-1}$ for C-F vibrations of the PVDF block $[30,48]$. The spectra clearly indicate the presence of both monomer units in the products. 

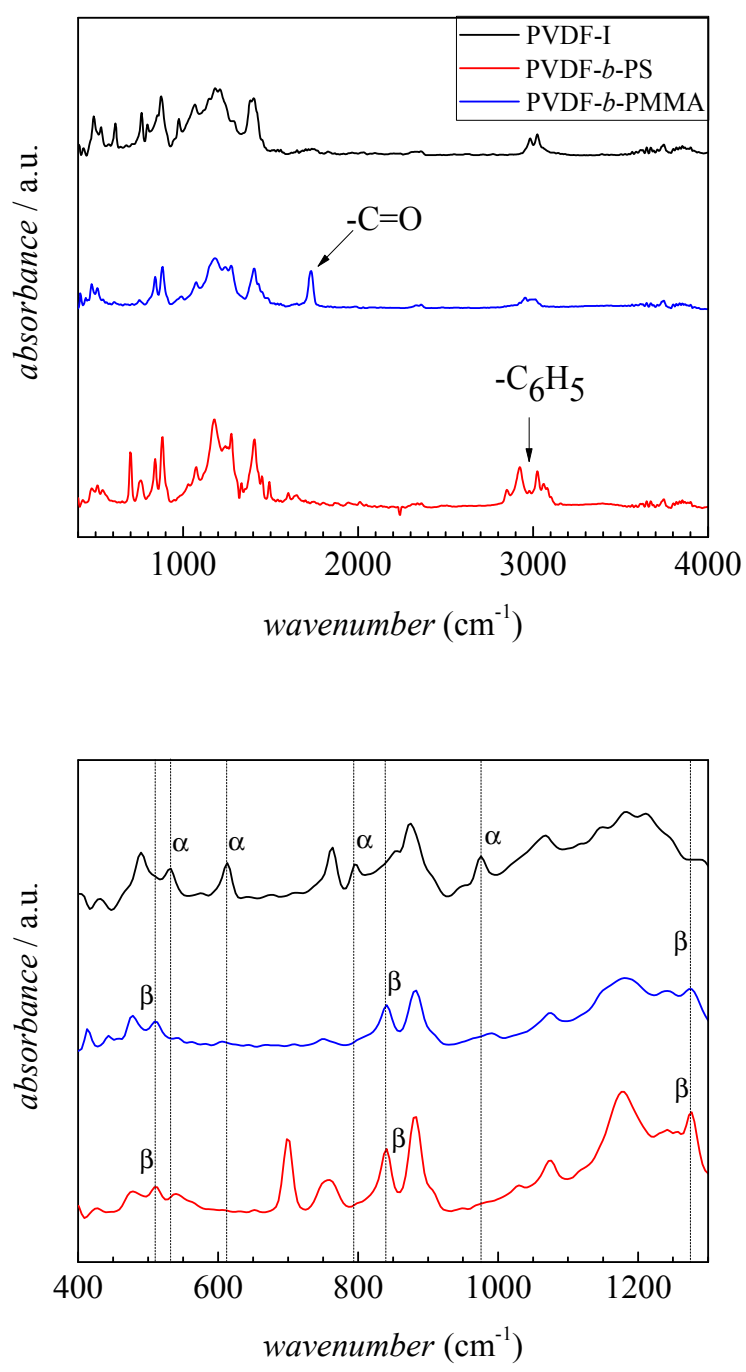

Figure 6. FT-IR results of PVDF-I (black), PVDF- $b$-PMMA (blue, sample 1), and PVDF- $b$-PS (red, sample 9). The vertical lines indicate peaks that are representative of either the $\alpha$ or $\beta$ crystalline phase of PVDF.

To obtain information on the crystallinity of the PVDF block, the enlarged spectra in the wavenumber range from 500 to $1300 \mathrm{~cm}^{-1}$ depicted in the lower part of Figure 6 are considered. The spectrum of the PVDF-I macroinitiator shows distinct peaks at 532, 614, 795, and $976 \mathrm{~cm}^{-1}$ indicating the presence of $\alpha$ phase PVDF. On the contrary, the spectra of the block copolymers show none of the above mentioned peaks. New peaks at 510, 841 , and $1276 \mathrm{~cm}^{-1}$ occur, which suggest the presence of $\beta$ crystalline PVDF domains in the copolymer. Thus, the formation of PVDF- $b$-PMMA or PVDF- $b$-PS is suggested to be associated with a change in crystallinity of the PVDF segments.

The peak at $841 \mathrm{~cm}^{-1}$ in the IR spectrum may also be indicative of $\gamma$ phase material, however, peaks at $776,812,833$, and $1234 \mathrm{~cm}^{-1}$ also typical for the $\gamma$ phase are not seen. As pointed out in literature, the flawless identification of $\beta$ phase PVDF requires additional analyses such as XRD [13]. The results from XRD of PVDF-I and two block copolymers (sample 1 and 9 in Table 1) are depicted in Figure 7. The spectra are clearly different. The PVDF-I curve shows peaks at $2 \theta$ values of $17.66^{\circ}, 18.30^{\circ}$, $19.90^{\circ}$, and $26.56^{\circ}$, which are related to the $\alpha$ phase [13]. On the other hand for the block copolymers only one peak with a maximum at around $20.26^{\circ}$ is observed, which indicates the presence of $\beta$ phase material. Peaks typical for the $\gamma$ phase at $2 \theta$ values of $18.50^{\circ}, 19.20^{\circ}$ or $20.04^{\circ}$ are not found [13]. Thus, the results from FT-IR and XRD strongly suggest the transformation of $\alpha$ to $\beta$ phase PVDF domains in the copolymer. In addition, DSC analyses yield melting temperatures of $165^{\circ} \mathrm{C}$ for the 
block copolymers and $172{ }^{\circ} \mathrm{C}$ for the PVDF macroinitiator. These temperatures are characteristic for $\alpha$ and $\beta$ phase material. Since $\gamma$ phase PVDF is associated with melting temperatures between 180 and $190{ }^{\circ} \mathrm{C}[13]$ the presence of $\gamma$ phase PVDF can be excluded.

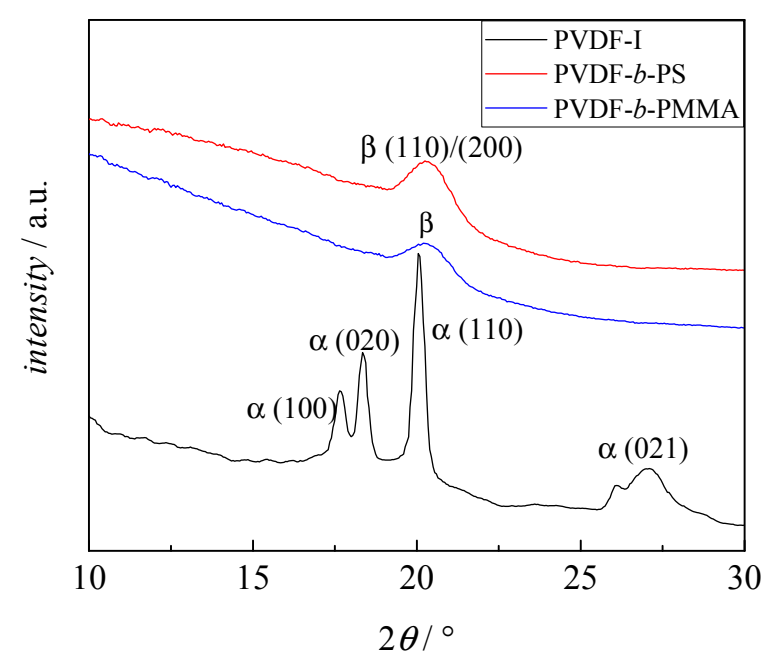

Figure 7. XRD results of PVDF-I (black), block copolymer with MMA (sample 4, blue) and block copolymer with styrene (sample 11, red).

The results demonstrate that the crystal structure of PVDF moieties is transformed from $\alpha$ to $\beta$ after block copolymer synthesis. To identify which ratio of PVDF block length, $n_{\mathrm{PVDF}}$, to comonomer block length, $n_{\mathrm{co}}$, is required for this transformation a number of block copolymers was synthesized. For $n_{\mathrm{VDF}} / n_{\mathrm{co}}$ ranging from 0.25 to 100 the characteristic IR peaks assigned to $\beta$ phase material were found. In addition, contributions from $\alpha$ phase were observed. In cases where this ratio was between 1.4 and 5 exclusively the IR peaks indicative of $\beta$ phase material were detected. With decreasing block length ratio $n_{\mathrm{PVDF}} / n_{\mathrm{co}}$ the fraction of crystalline material is reduced. In addition to the block length ratio, the absolute lengths of both blocks is important to be considered. The data presented here refer to PVDF segments with lengths between 27 and 153 monomer units. In future, longer PVDF segments need to be used as well.

According to references [16,48-50] the miscibility of PVDF and PMMA does not depend on temperature, which is attributed to interactions between the carbonyl group of PMMA and the dipole moment of PVDF as well as hydrogen bonding. Because of steric reasons, the above-mentioned interactions lead to an all trans conformation in both polymers. Further, the presence of MMA units may alter the glass transition temperature of PVDF, which affects the relative growth rates of $\alpha$ and $\beta$ polymorphs [16].

According to dynamic mechanical measurements, pure PVDF may undergo four relaxations when frequency and temperature are changed [51,52]. One of these relaxations, which is associated with the glass transition may be shifted to higher frequencies and pressures after addition of PMMA. Essentially, PMMA facilitates relaxation from a lower energy level, which may be explained by breaking the interactions and correlations between the PVDF permanent moments in the amorphous-crystalline-interphase and improving the dielectric relaxation possibilities [16].

The piezoelectricity and pyroelectricity of PVDF are associated with the existence of a remnant polarization that is proportional to the degree of crystallinity [16]. PMMA, as the amorphous phase, surrounds individual crystallites, and therefore, affects the degree of crystallinity.

Figure 8 compares the XRD results of samples 6, 7, and 8 with PMMA volume fractions of $33 \%, 46 \%$, and $66 \%$, respectively, in the block copolymer. While it is clearly seen that no significant contributions from $\alpha$ phase are contained, a quantitative comparison of the XRD results of different samples is not feasible. However, the DSC results show that the integration of the melting peak and 
the degree of crystallinity are proportional to block lengths ratio and volume fraction of PMMA in the block copolymer. In all cases, the integrals of the melting peak and the degree of crystallinity decrease, if the volume fraction of PMMA in the block copolymer increases.

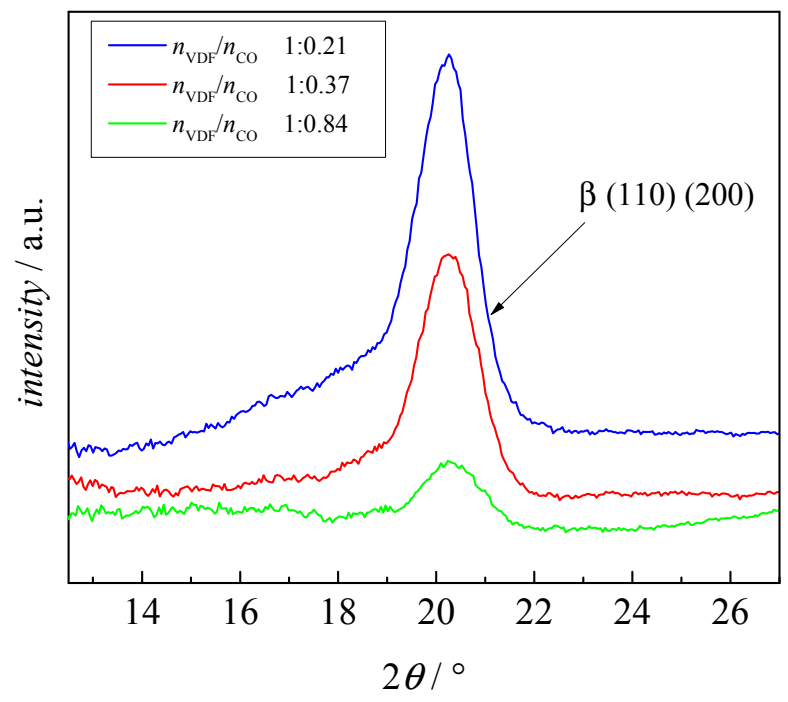

Figure 8. XRD curves for sample 6 (blue), 7 (red), and 8 (green) with the block length ratios as indicated.

Interestingly the block copolymers with PS as second block also show $\beta$ phase crystallinity. The reason for this behavior is not yet clear. It may be suspected that the aromatic groups are directing the conformation to an all trans structure of PVDF. For low molecular weight species interactions between $\mathrm{F}$ atoms and for example aromatic rings were reported [53-56].

\subsection{Phase Separation}

To test for microphase separation of the two polymer blocks, AFM analyses of thin films of samples 4, 6, 10, and 11 obtained by spin coating on mica were carried out. Without selective etching of the PMMA or PS block by air-plasma, flat films were obtained that did not show any phase separation as indicated by the phase-image of the AFM (not shown). The phase-image contrasts in a semi-quantitative way differences in the material properties, e.g., hardness and viscoelasticity. After 10 $\mathrm{s}$ of air plasma treatment for every sample, a height variation in the topography image on the left hand side of Figures 9-12 is visible and the phase image on the right hand side of these figures shows small domains in a continuous matrix. These domains may be associated with a PVDF-rich microphase and the size of these domains scales with the volume fraction of PVDF in the copolymer. In Figures 9 and 10, it is notable that the continuous matrix in which the PVDF-domains are embedded covers a much smaller surface fraction in sample 6 compared to sample 4 . This observation corresponds with the lower PMMA volume fraction of $\varphi_{\mathrm{co}}=0.33$ in sample 6 compared to $\varphi_{\mathrm{co}}=0.85$ in sample 4 . Control experiments with blends of PMMA and PVDF homopolymers showed no phase separation.

AFM measurements at identical conditions were carried out for two copolymers with styrene blocks of different length (Figures 11 and 12). As expected, the size of the domains are proportional to the PVDF volume fraction in the copolymer. In Figure 12, it is notable that the continuous matrix containing the PVDF-domains covers a smaller surface fraction in sample 10 compared to sample 11 (Figure 11) because of the lower value of $\varphi_{\mathrm{co}}=0.50$ compared to $\varphi_{\mathrm{co}}=0.58$, respectively. 


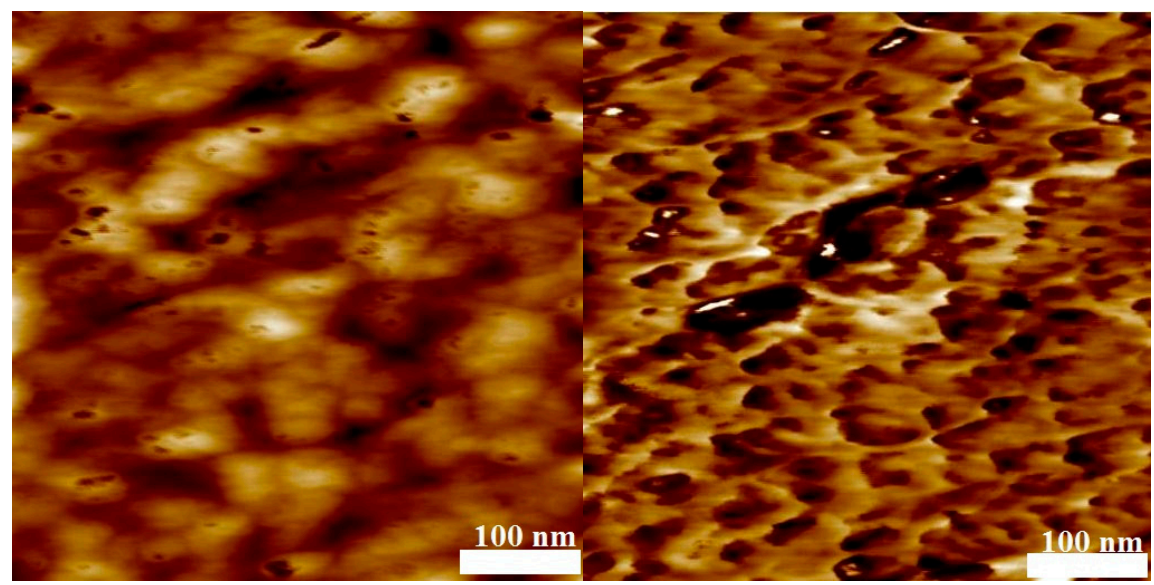

Figure 9. Atomic Force Microscopy (AFM) results of the block copolymer with MMA (sample 6) with $M_{\mathrm{n}}=12,080 \mathrm{~g} \cdot \mathrm{mol}^{-1}$ after $10 \mathrm{~s}$ of air-plasma treatment. Topography ((left) height scale: $\left.5 \mathrm{~nm}\right)$ and phase image ((right) phase scale: $\left.90^{\circ}\right)$, Average domain size $=50 \mathrm{~nm}$.

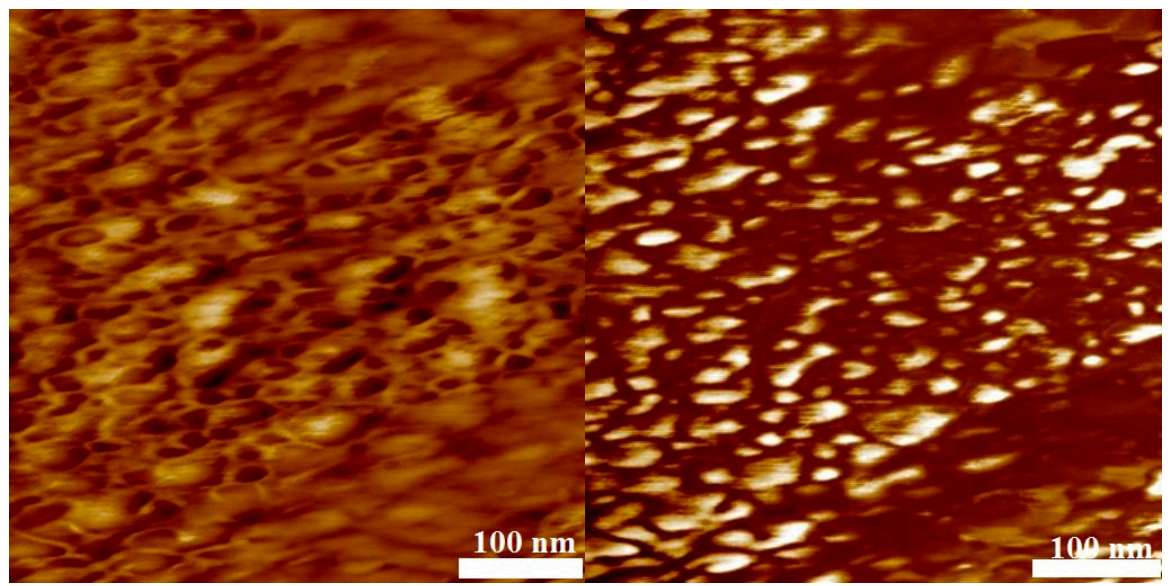

Figure 10. AFM results of the block copolymer with MMA (sample 4, $M_{\mathrm{n}}=39,450 \mathrm{~g} \cdot \mathrm{mol}^{-1}$ ) after $10 \mathrm{~s}$ of air plasma treatment. Topography ((left) height scale: $10 \mathrm{~nm})$ and phase image ((right) phase scale: $50^{\circ}$ ), average domain size $=75 \mathrm{~nm}$.

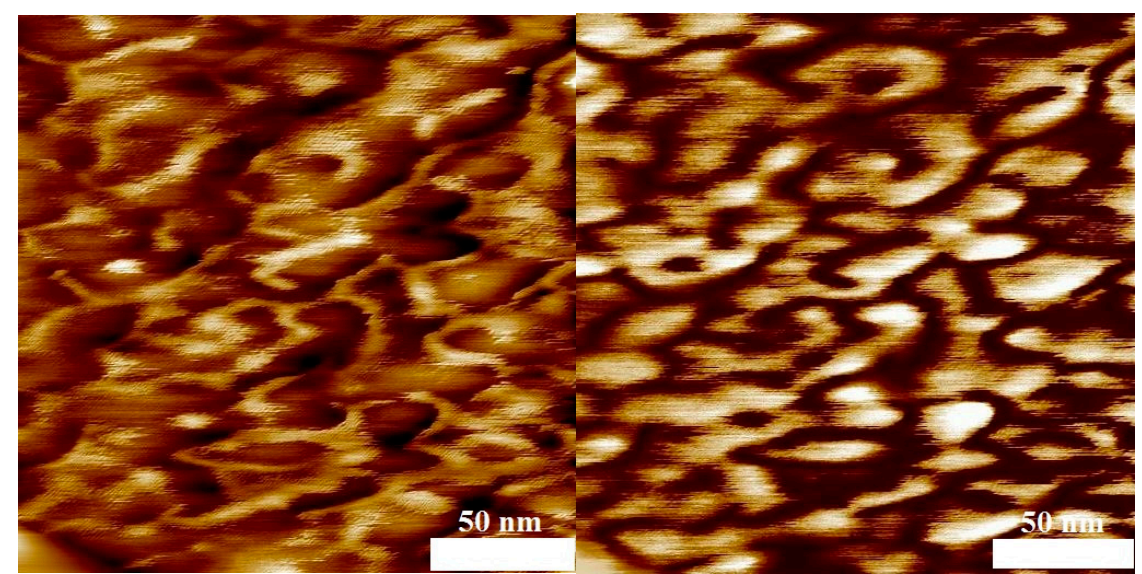

Figure 11. AFM results of the block copolymer with styrene (sample $11, M_{n}=19,856 \mathrm{~g} \cdot \mathrm{mol}^{-1}$ ) after $10 \mathrm{~s}$ of air-plasma treatment. Topography ((left) height scale: $10 \mathrm{~nm})$ and phase image ((right) phase scale: $\left.30^{\circ}\right)$, average domain size $=80 \mathrm{~nm}$. 


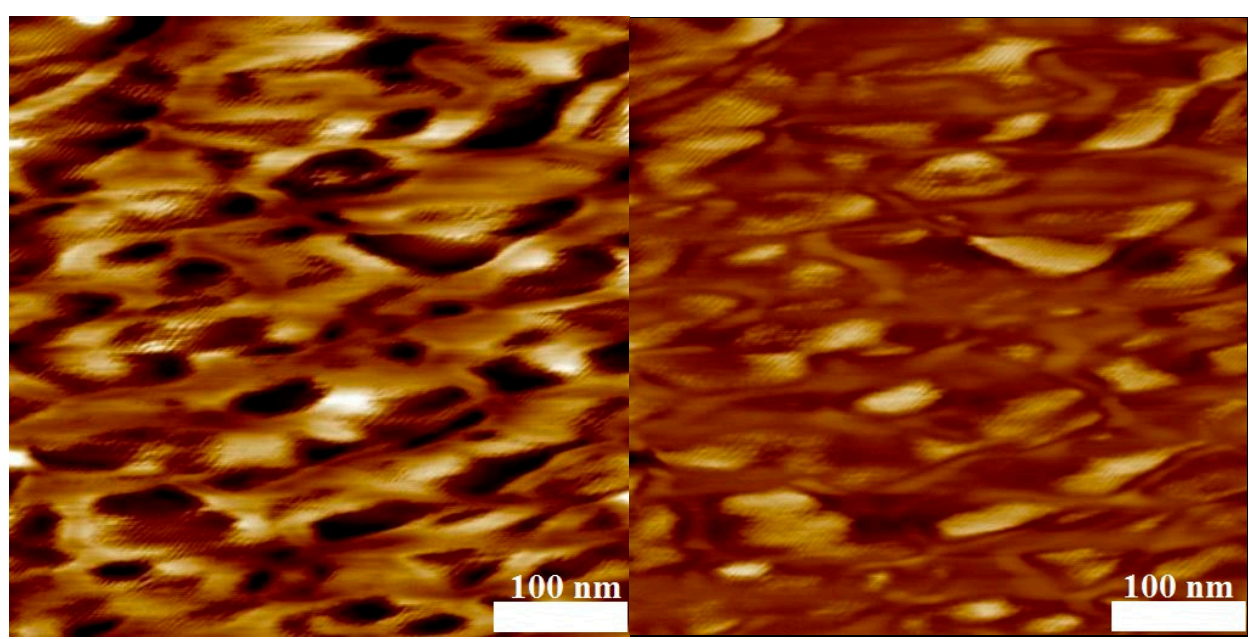

Figure 12. AFM results of the block copolymer with styrene (sample 10, $M_{n}=33,040 \mathrm{~g} \cdot \mathrm{mol}^{-1}$ ) after $10 \mathrm{~s}$ of air-plasma treatment. Topography ((left) height scale: $10 \mathrm{~nm})$ and phase image ((right) phase scale: $90^{\circ}$ ), average domain size $=120 \mathrm{~nm}$.

\section{Conclusions}

PVDF-I obtained from iodine transfer polymerization served as macroinitiator for MMA and styrene polymerization. Due to four well-known propagation reactions in VDF polymerizations, two types of PVDF end groups were obtained: $\mathrm{CF}_{2}-\mathrm{CH}_{2}-\mathrm{I}$ and $\mathrm{CH}_{2}-\mathrm{CF}_{2}-\mathrm{I}$, which have very different reactivities. Following Asandei et al. the entire polymer material may be functionalized upon UV irradiation of $\mathrm{Mn}_{2}(\mathrm{CO})_{10}$ in the presence of PVDF-I [31]. ${ }^{\bullet} \mathrm{Mn}(\mathrm{CO})_{5}$ radicals obtained due to UV irradiation abstract iodine from both PVDF-I end groups. The resulting PVDF radicals initiate MMA and styrene free radical polymerizations leading to block copolymers of VDF and MMA or styrene, as indicated by SEC analyses and NMR spectra.

FTIR spectra suggest that the crystal phase is transformed from the $\alpha$ phase in case of PVDF-I to $\beta$ phase PVDF-domains in case of the block copolymers. XRD measurements confirmed the transformation from $\alpha$ to $\beta$ crystalline phase. Varying block length ratios $n_{\mathrm{VDF}} / n_{\mathrm{co}}$ from 0.25 to 100 resulted in $\beta$ phase crystallinity. For ratios from 1.4 to 5 exclusively $\beta$ phase material was detected. AFM results indicate a phase separation of the PVDF-segments from the other polymer, PMMA or PS. Mixtures of corresponding homopolymers do not show a distinct phase separation in the AFM images. The data indicates that the volume fraction of both monomer units within the block copolymers affects the structure formation.

Supplementary Materials: The following are available online at www.mdpi.com/2073-4360/9/8/306/s1, Figure S1: A comparison of ${ }^{19} \mathrm{~F}$ NMR spectra of PVDF-I (blue) and the corresponding PVDF- $b$-PMMA (red, sample 1 in Table 1).

Acknowledgments: We are grateful to Dipl. Ing. Simone Wolff (Institute for Technical Thermodynamics and Refrigeration, Karlsruhe Institute of Technology (KIT)) for some of our XRD measurements. Florian Brandl is acknowledged for preparing I-PVDF-I by emulsion polymerization. We are thankful to Martina Heinz for the SEC and Ulrike Koecher for DSC analyses. The Institute of Organic Chemistry (TU-Clausthal) is acknowledged for performing the NMR analyses.

Author Contributions: The PVDF synthesis in supercritical $\mathrm{CO}_{2}$, the synthesis of the block copolymers, FT-IR and AFM measurements were carried out by Nahal Golzari. Jörg Adams performed the XRD analyses at TU Clausthal. The manuscript was prepared by Nahal Golzari, Jörg Adams, and Sabine Beuermann.

Conflicts of Interest: The authors declare no conflict of interest. 


\section{References}

1. Humphrey, J.S.; Amin-Sanayei, R. Vinylidene Fluoride Polymers. In Encyclopedia of Polymer Science and Technology, 3rd ed.; Wiley: New York, NY, USA, 2002; pp. 510-533.

2. Scheirs, J. Modern Fluoropolymers: High Performance Polymers for Diverse Applications; Wiley: Chichester, UK; New York, NY, USA, 1997; ISBN 978-0-471-97055-2.

3. Ameduri, B. From Vinylidene Fluoride (VDF) to the Applications of VDF-Containing Polymers and Copolymers: Recent Developments and Future Trends. Chem. Rev. 2009, 109, 6632-6686. [CrossRef] [PubMed]

4. Beuermann, S.; Imran-ul-haq, M. Homogeneous phase polymerization of vinylidene fluoride in supercritical $\mathrm{CO}_{2}$ : Surfactant free synthesis and kinetics. Macromol. Symp. 2007, 259, 210-217. [CrossRef]

5. Lu, F.J.; Hsu, S.L. Study of the crystallization behavior of poly(vinylidene fluoride) from melt under the effect of an electric field. Macromolecules 1986, 19, 326-329. [CrossRef]

6. Kawai, H. The Piezoelectricity of Poly(vinylidene fluoride). Jpn. J. Appl. Phys. 1969, 8, 975-976. [CrossRef]

7. Bergman, J.G., Jr.; Mcfee, J.H.; Crane, G.R. Pyroelectricity and optical second harmonic generation in poly(vinylidene fluoride) films. Appl. Phys. Lett. 1971, 18, 203. [CrossRef]

8. Nakamura, K.; Wada, Y. Piezoelectricity, pyroelectricity, and the electrostriction constant of poly(vinylidene fluoride). J. Polym. Sci. Part B Polym. Phys. 1971, 9, 161-173. [CrossRef]

9. Lovinger, A.J. Molecular Mechanism for $\alpha$ ( $\delta$ Transformation in Electrically Poled Poly(vinylidene fluoride)). Macromolecules 1981, 14, 225-227. [CrossRef]

10. Kepler, R.G. Ferroelectric, Pyroelectric, and Piezoelectric Properties of Poly(vinylidene fluoride) in Ferroelectric Polymers Chemistry, in Physics and Applications; Nalwa, H.S., Ed.; CRC Press: New York, NY, USA, 1995; p. 183, ISBN 0-8247-9468-0.

11. Hasegawa, R.; Kobayashi, M.; Tadokoro, H. Molecular conformation and packing of poly(vinylidene fluoride). Stability of three crystalline forms and the effect of high pressure. Polym. J. 1972, 3, 591-599. [CrossRef]

12. Lovinger, A.; Reed, D. Inhomogeneous Thermal Degradation of Poly(vinylidene fluoride) Crystallized from the Melt. Macromolecules 1980, 13, 989-994. [CrossRef]

13. Martins, P.; Lopes, A.C.; Lanceros-Mendez, S. Electroactive phases of poly(vinylidene fluoride): Determination, processing and applications. Prog. Polym. Sci. 2014, 39, 683-706. [CrossRef]

14. Fukada, E. History and recent progress in piezoelectric polymers. IEEE Trans. Ultrason. Ferroelectr. Freq. Control 2000, 47, 1277-1290. [CrossRef] [PubMed]

15. Bauer, F. Relaxor fluorinated polymers: Novel applications and recent developments. IEEE Trans. Dielectr. Electr. Insul. 2010, 17, 1106-1112. [CrossRef]

16. Jungnickel, B.J. PVDF and Its Blends. In Ferroelectric Polymers Chemistry, in Physics and Applications; Nalwa, H.S., Ed.; CRC Press: New York, NY, USA, 1995; p. 183, ISBN 0-8247-9468-0.

17. Valade, D.; Boyer, C.; Ameduri, B.; Boutevin, B. Poly(vinylidene fluoride)-b-poly(styrene) Block Copolymers by Iodine Transfer Polymerization (ITP): Synthesis, Characterization, and Kinetics of ITP. Macromolecules 2006, 39, 8639-8651. [CrossRef]

18. Boutevin, B. From telomerization to living radical polymerization. J. Polym. Sci. Part A Polym. Chem. 2000, 38, 3235-3243. [CrossRef]

19. David, G.; Boyer, C.; Tonnar, J.; Ameduri, B.; Lacroix-Desmazes, P.; Boutevin, B. Use of Iodocompounds in Radical Polymerization. Chem. Rev. 2006, 106, 3936-3962. [CrossRef] [PubMed]

20. Boyer, C.; Valade, D.; Sauguet, L.; Ameduri, B.; Boutevin, B. Iodine Transfer Polymerization (ITP) of Vinylidene Fluoride (VDF). Influence of the defect of VDF chaining on the control of ITP. Macromolecules 2005, 38, 10353-10362. [CrossRef]

21. Girard, E.; Marty, J.D.; Ameduri, B.; Destarac, M. Direct synthesis of Vinylidene Fluoride-Based Amphiphilic Diblock Copolymers by RAFT/MADIX Polymerization. ACS Macro Lett. 2012, 1, 270-274. [CrossRef]

22. Guerre, M.; Campagne, B.; Gimello, O.; Parra, K.; Ameduri, B.; Ladmiral, V. Deeper Insight into the MADIX Polymerization of Vinylidene Fluoride. Macromolecules 2015, 48, 7810-7822. [CrossRef]

23. Guerre, M.G.; Lopez, T.; Soulestin, C.; Totée, B.; Améduri, G.; Silly, V.; Ladmiral, A. Journey into the Microstructure of PVDF Made by RAFT. Macromol. Chem. Phys. 2016, 217, 2275-2285. [CrossRef] 
24. Monteiro, M.J.; Adamy, M.M.; Leeuwen, B.J.; van Herk, A.M.; Destarac, M. A “Living” Radical ab Initio Emulsion Polymerization of Styrene Using a Fluorinated Xanthate Agent. Macromolecules 2005, 38, 1538-1541. [CrossRef]

25. Guerre, M.; Schmidt, J.; Talmon, Y.; Ameduri, B.; Ladmiral, V. An amphiphilic poly(vinylidene fluoride)- $b$-poly(vinyl alcohol) block copolymer: Synthesis and self-assembly in water. Polym. Chem. 2017, 8, 1125-1128. [CrossRef]

26. Guerre, M.; Uchiyama, M.; Folgado, E.; Semsarilar, M.; Ameduri, B.; Satoh, K.; Kamigato, M.; Ladmiral, V. Combination of Cationic and Radical RAFT Polymerizations: A Versatile Route to Well-Defined Poly(ethyl vinyl ether)-block-poly(vinylidene fluoride) Block Copolymers. ACS Macro Lett. 2017, 6, 393-398. [CrossRef]

27. Boyer, C.; Valade, D.; Lacroix-Desmazes, P.; Ameduri, B.; Boutevin, B. Kinetics of the Iodine Transfer Polymerization of Vinylidene Fluoride. J. Polym. Sci. Part A Polym. Chem. 2006, 44, 5763-5777. [CrossRef]

28. Vukićević, R.; Vukovic, I.; Stoyanov, H.; Korwitz, A.; Pospiech, D.; Kofod, G.; Loos, K.; Brinke, G.; Beuermann, S. Poly(vinylidene fluoride)-functionalized single-walled carbon nanotubes for the preparation of composites with improved conductivity. Polym. Chem. 2012, 3, 2261-2265. [CrossRef]

29. Vukićević, R.; Hirzenberger, P.; Hild, S.; Beuermann, S. Functionalization of carbon black nanoparticles with poly(vinylidene fluoride). J. Polym. Sci. Part A Polym. Chem. 2010, 48, 4847-4854. [CrossRef]

30. Vukićević, R.; Schwadtke, U.; Schmücker, S.; Schäfer, P.; Kuckling, D.; Beuermann, S. Alkyne-azide coupling of tailored poly(vinylidene fluoride) and polystyrene for the synthesis of block copolymers. Polym. Chem. 2012, 3, 409-414. [CrossRef]

31. Asandei, A.D.; Adebolu, O.I.; Simpson, C.P. Mild-Temperature $\mathrm{Mn}_{2}(\mathrm{CO})_{10}$-Photomediated Controlled Radical Polymerization of Vinylidene Fluoride and Synthesis of Well-Defined Poly(vinylidene fluoride) Block Copolymers. J. Am. Chem. Soc. 2012, 134, 6080-6083. [CrossRef] [PubMed]

32. Simpson, C.P.; Adebolu, O.I.; Kim, J.-S.; Vasu, V.; Asandei, A.D. Metal and Ligand Effects of Photoactive Transition Metal Carbonyls in the Iodine Degenerative Transfer Controlled Radical Polymerization and Block Copolymerization of Vinylidene Fluoride. Macromolecules 2015, 48, 6404-6420. [CrossRef]

33. Asandei, A.D. Photomediated Controlled Radical Polymerization and Block Copolymerization of Vinylidene Fluoride. Chem. Rev. 2016, 116, 2244-2247. [CrossRef] [PubMed]

34. Rowlands, G.J. Radicals in organic synthesis. Part 1. Tetrahedron 2009, 65, 8603-8655. [CrossRef]

35. Goodman, J.L.; Peters, K.S.; Vaida, V. The Determination of the Mn-Mn Bond Strength in $\mathrm{Mn}_{2}(\mathrm{CO})_{10} \mathrm{Using}$ Pulsed Time Resolved Photoacoustic Calorimetry. Organometallics 1986, 5, 815-816. [CrossRef]

36. Sarakha, M.; Ferraudi, G. Photophysical Features of the $\mathrm{M}_{2}(\mathrm{CO})_{10}, \mathrm{M}=\mathrm{Mn}$ and Re, Solution Photochemistry. Inorg. Chem. 1999, 38, 4605-4607. [CrossRef] [PubMed]

37. Voet, V.S.D.; Hermida-Merino, D.; ten Brinke, G.; Loos, K. Block copolymer route towards poly(vinylidene fluoride)/poly(methacrylic acid)/nickel nanocomposites. RSC Adv. 2013, 3, 7938-7946. [CrossRef]

38. Voet, V.S.D.; Alberda van Ekenstein, G.O.R.; Meereboer, N.L.; Hofman, A.H.; ten Brinke, G.; Loos, K. Double-crystalline PLLA- $b$-PVDF- $b$-PLLA triblock copolymers: Preparation and crystallization. Polym. Chem. 2014, 5, 2219-2230. [CrossRef]

39. Voet, V.S.D.; Tichelaar, M.; Tanase, S.; Mittelmeijer-Hazeleger, M.C.; ten Brinke, G.; Loos, K. Poly(vinylidene fluoride)/nickel nanocomposites from semicrystalline block copolymer precursors. Nanoscale 2013, 5, 184-192. [CrossRef] [PubMed]

40. Beuermann, S.; Imran-ul-haq, M. Homogeneous Phase Polymerization of Vinylidene Fluoride in Supercritical Carbon Dioxide. J. Polym. Sci. Part A Polym. Chem. 2007, 45, 5626-5635. [CrossRef]

41. Möller, E.; Beuermann, S. Homogeneous Phase Copolymerizations of Vinylidene Fluoride and Hexafluoropropene in Supercritical Carbon Dioxide. Macromol. React. Eng. 2011, 5, 8-21. [CrossRef]

42. Brandl, F.; Beuermann, S. Halb-kontinuierliche Emulsionspolymerisation von Vinylidenfluorid. Chem. Ing. Tech. submitted.

43. Nick, L.; Kindermann, A.; Fuhrmann, J. Morphological studies of spin-coated films of poly(styrene-blockmethyl methacrylate) copolymers by atomic force microscopy. Colloid Polym. Sci. 1994, 272, 367-371. [CrossRef]

44. Gallot-Grubisic, Z.; Rempp, P.; Benoit, H.J. A universal calibration for gel permeation chromatography. Polym. Sci. Part B Polym. Lett. 1967, 5, 753-759. [CrossRef]

45. Siegmann, R.; Drache, M.; Beuermann, S. Propagation rate coefficients for vinylidene fluoride homopolymerizations. Macromolecules 2013, 46, 9507-9514. [CrossRef] 
46. Guiot, J.; Ameduri, B.; Boutevin, B. Radical Homopolymerization of Vinylidene Fluoride Initiated by tert-Butyl Peroxypivalate. Investigation of the Microstructure by ${ }^{19} \mathrm{~F}$ and ${ }^{1} \mathrm{H}$ NMR Spectroscopies and Mechanisms. Macromolecules 2002, 35, 8694-8707. [CrossRef]

47. Balague, J.; Ameduri, B.; Boutevin, B.; Caporiccio, G. Controlled step-wise telomerization of vinylidene fluoride, hexafluoropropene and trifluoroethylene with iodofluorinated transfer agents. J. Fluor. Chem. 2000, 102, 253-268. [CrossRef]

48. Hesse, M.; Meier, H.; Zeeh, B. Spektroskopische Methoden in der Organischen Chemie, 7th ed.; Thieme: Stuttgart, Germany, 2005.

49. Paul, D.R.; Altamirano, J.O. Properties of compatible blends of poly(vinylidene fluoride) and poly(methyl methacrylate). Adv. Chem. Ser. 1975, 142, 371-385. [CrossRef]

50. Noland, J.S.; Hsu, N.N.; Schmitt, J.M. Compatible high polymers: Poly(vinylidene fluoride) blends with homopolymers of methyl and ethyl methacrylate. Adv. Chem. Ser. 1971, 99, 15-28. [CrossRef]

51. Yano, S. Dielectric relaxation and molecular motion in poly(vinylidene fluoride). J. Polym. Sci. Part B Polym. Phys. 1970, 8, 1057-1072. [CrossRef]

52. Kakutani, H. Dielectric absorption in oriented poly(vinylidene fluoride). J. Polym. Sci. Part B Polym. Phys. 1970, 8, 1177-1186. [CrossRef]

53. Li, P.; Maier, J.M.; Vik, E.C.; Yehl, C.J.; Dial, B.E.; Rickher, A.E.; Smith, M.D.; Pellechia, P.J.; Shimizu, K.D. Stabilizing Fluorine- $\pi$ Interactions. Angew. Chem. Int. Ed. 2017, 56, 7209-7212. [CrossRef] [PubMed]

54. Hunter, L. The C-F bond as a conformational tool in organic and biological chemistry. Beilstein J. Org. Chem. 2010, 6, 38. [CrossRef] [PubMed]

55. O'Hagan, D. Understanding organofluorine chemistry. An introduction to the C-F bond. Chem. Soc. Rev. 2008, 37, 308-319. [CrossRef] [PubMed]

56. Hof, F.; Scofield, D.M.; Schweizer, W.B.; Diederich, F. A weak attractive interaction between organic fluorine and an amide group. Angew. Chem. Int. Ed. 2004, 43, 5056-5059. [CrossRef] [PubMed]

(C) 2017 by the authors. Licensee MDPI, Basel, Switzerland. This article is an open access article distributed under the terms and conditions of the Creative Commons Attribution (CC BY) license (http:/ / creativecommons.org/licenses/by/4.0/). 